EXPERIMENTAL STUDY

\title{
Nitric oxide stimulates glucose transport through insulin-independent GLUT4 translocation in 3T3-L1 adipocytes
}

Takashi Tanaka, Kaname Nakatani ${ }^{1}$, Kohei Morioka, Hideki Urakawa, Noriko Maruyama, Nagako Kitagawa, Akira Katsuki, Rika Araki-Sasaki, Yasuko Hori, Esteban C Gabazza, Yutaka Yano, Hideo Wada ${ }^{1}$, Tsutomu Nobori ${ }^{1}$, Yasuhiro Sumida and Yukihiko Adachi

Third Department of Internal Medicine and ${ }^{1}$ Department of Laboratory Medicine, Mie University School of Medicine, 2-174 Edobashi, Tsu, Mie 514-8507, Japan

(Correspondence should be addressed to K Nakatani; Email: nakatani@clin.medic.mie-u.ac.jp)

\begin{abstract}
Objective: It is well known that nitric oxide synthase (NOS) is expressed and that it modulates glucose transport in skeletal muscles. Recent studies have shown that adipose tissues also express inducible and endothelial nitric oxide synthase (eNOS). In the present study, we investigated whether nitric oxide (NO) induces glucose uptake in adipocytes, and the signaling pathway involved in the NOstimulated glucose uptake in 3T3-L1 adipocytes.

Methods: First, we determined the expression of eNOS in 3T3-L1 adipocytes, and then these cells were treated with the NO donor sodium nitroprusside (SNP) and/or insulin, and glucose uptake and phosphorylation of insulin receptor substrate (IRS)-1 and Akt were evaluated. Moreover, we examined the effects of a NO scavenger, a guanylate cyclase inhibitor or dexamethasone on SNP-stimulated glucose uptake and GLUT4 translocation.

Results: SNP at a concentration of $50 \mathrm{mmol} / \mathrm{l}$ increased 2-deoxyglucose uptake (1.8-fold) without phosphorylation of IRS-1 and Akt. Treatment with the NO scavenger or guanylate cyclase inhibitor decreased SNP-stimulated glucose uptake to the basal level. Dexamethasone reduced both insulinand SNP-stimulated glucose uptake with impairment of GLUT4 translocation.

Conclusion: NO is capable of stimulating glucose transport through GLUT4 translocation in 3T3-L1 adipocytes, via a mechanism different from the insulin signaling pathway.
\end{abstract}

European Journal of Endocrinology 149 61-67

\section{Introduction}

Nitric oxide (NO) is an important mediator with a wide variety of biological functions including the control of blood vessel tone and neurotransmission. It is known that NO is released from skeletal muscles and a great body of evidence has shown that NO plays a critical role in glucose metabolism (1). For example, the administration of NO synthase (NOS) inhibitors induce remarkable insulin resistance (2), NO donors stimulate glucose transport in skeletal muscles (3-5), and endothelial nitric oxide synthase (eNOS) knockout mice have insulin resistance (6). Thus, NO may be an important modulator of glucose metabolism. The NO-stimulated glucose uptake is not inhibited by wortmannin, an inhibitor of phosphatidylinositol 3-kinase (PI3K). PI3K is a downstream effector of insulin receptor, and this effect of NO appears to be independent of the insulin signaling pathway. It has been proposed that NO mediates contraction-stimulated glucose transport in skeletal muscles $(5,7)$. However, in a recent study, NOS inhibitors failed to affect contraction-stimulated glucose transport in isolated muscles, suggesting that NO is not involved in the signaling pathway of contraction-stimulated glucose uptake in skeletal muscles, and that NO donor increases skeletal muscle glucose uptake through a mechanism distinct from the insulin- and contraction-signaling pathways (8). The physiological significance of this insulin- and contraction-independent signaling of glucose uptake induced by NO in skeletal muscles is unclear.

The synthesis of NO is catalyzed by a family of NOS (9), among which there are three isoforms: endothelial NOS (eNOS), neuronal NOS (nNOS) and inducible NOS (iNOS) (10). Of these isoforms, nNOS and eNOS are expressed in skeletal muscles (11), where generated NO mediates glucose transport. In addition, some of 
the effects of NO depend on the activation of soluble guanylate cyclase and on the increased level of intracellular cyclic GMP (12).

Regarding another major organ of glucose metabolism, previous studies have shown that norepinephrine stimulates iNOS activity and NO release from brown adipose tissue (BAT) (13, 14). Recent studies have also corroborated the expression and function of both eNOS and iNOS in BAT (15). However, the expression of NOS and the role of NO in white adipose tissue (WAT) remain unclear. In the present study, we hypothesized that, as it does in skeletal muscles, NO mediates glucose transport in WAT where a high rate of glucose uptake also takes place. To test this hypothesis, we investigated the expression of NOS and the effect of the NO donor sodium nitroprusside (SNP) on glucose uptake in 3T3-L1 adipocytes, which have been shown to be a good model for studying the functions of WAT. We also investigated whether the mechanism of NO-stimulated glucose uptake in 3T3-L1 adipocytes is similar to that in skeletal muscles.

\section{Materials and methods}

\section{Materials}

Anti-eNOS and anti-iNOS antibodies were purchased from Transduction Laboratories (Lexington, KY, USA). Anti-phosphotyrosine monoclonal antibody (Py20) was from Upstate Biotechnology (Lake Placid, NY, USA), anti-Akt antibody and anti-phosphoAkt (Ser 473) antibodies from Cell Signaling Technology (Beverly, MA, USA), anti-insulin receptor substrate-1 (anti-IRS-1) polyclonal antibody from Santa Cruz Biotechnology (Santa Cruz, CA, USA) and anti-GLUT1 antibody from Chemicon (Temecula, CA, USA). AntiGLUT4 antibody against the C-terminal region of GLUT4 was raised in rabbits. Tissue culture medium, antibiotic solutions, lipopolysaccharide (LPS, 0127:B8), nitrobluetetrazorium (NBT) and 5-bromo4-chloro-3-indolyl phosphate (BCIP) were obtained from Sigma Chemical (St Louis, MO, USA). SNP, carboxy-PTIO (CPTIO) and LY83583 were from Calbiochem (San Diego, CA, USA). Protein G-Sepharose and radioisotope were from Amersham Pharmacia (Uppsala, Sweden), and secondary antibody from Promega (Madison, WI, USA). Other chemicals were from Wako Pure Chemicals (Osaka, Japan).

\section{Cell culture}

3T3-L1 fibroblasts were cultured in Dulbecco's modified Eagle's medium (DMEM) containing 10\% FCS in an atmosphere of $5 \% \mathrm{CO}_{2}$ at $37^{\circ} \mathrm{C}$. Fibroblasts were cultured up to confluency and then differentiation was induced by treating the cells with DMEM containing $0.5 \mathrm{mmol} / \mathrm{l} \quad 3$-isobutyl-1-methylxanthine, $\quad 4 \mu \mathrm{g} / \mathrm{ml}$ dexamethasone, $1 \mu \mathrm{g} / \mathrm{ml}$ insulin and 10\% FCS for
$48 \mathrm{~h}$. The cells were cultured in DMEM supplemented with 10\% FCS for the next 4-10 days. Cells were used only when at least $95 \%$ of the cells showed an adipocyte phenotype by accumulation of lipid droplets.

\section{Immunoprecipitation and immunoblotting}

For detection of NOS, the 3T3-L1 adipocytes were treated with $100 \mathrm{nmol} / \mathrm{l}$ insulin for $15 \mathrm{~min}$ or $50 \mathrm{mmol} / \mathrm{l}$ SNP for $60 \mathrm{~min}$; subsequent experiments were carried out in the same conditions. In addition, to evaluate the expression of iNOS the cells were incubated in the presence of $10 \mu \mathrm{g} / \mathrm{ml}$ LPS for $24 \mathrm{~h}$. After each treatment, the cells were lysed with the buffer containing $50 \mathrm{mmol} / \mathrm{l}$ Tris-HCl (pH 7.4), 1\% Triton X-100, 10\% glycerol, $150 \mathrm{mmol} / \mathrm{l} \mathrm{NaCl}, 1 \mathrm{mmol} / \mathrm{l}$ EDTA, $1 \mathrm{mmol} / \mathrm{l}$ dithiothreitol (DTT), and a protease inhibitor cocktail. Cell lysates were centrifuged at $15000 \boldsymbol{g}$ for $20 \mathrm{~min}$ and protein concentrations in the supernatants were determined using BCA protein assay kit (Pierce, Rockford, IL, USA). Each sample containing $1.5 \mathrm{mg}$ of protein was subjected to immunoprecipitation using protein G-Sepharose beads pre-coated with anti-eNOS or iNOS antibodies, and immunoblotted. The secondary antibody coupled to alkaline phosphatase was visualized using BCIP/NBT.

For IRS-1 phosphorylation assay, lysates of treated cells were subjected to immunoprecipitation using protein G-Sepharose beads pre-coated with anti-IRS-1, and immunoblotted with anti-IRS-1 or anti-phosphotyrosine antibody. For assay of Akt phosphorylation, lysates of treated cells were immunoblotted with anti-Akt or anti-phosphoAkt (Ser 473) antibodies. BCIP/NBT was used for visualization.

\section{Reverse-transcription PCR (RT-PCR)}

mRNAs of eNOS and iNOS were evaluated by RT-PCR. Total RNA was extracted from culture cells using RNeasy (Qiagen, Hilden, Germany). The quality and quantity of the RNA were determined by measuring the absorbance at 260 and $280 \mathrm{~nm}$. First-strand cDNA was synthesized using $2 \mu \mathrm{g}$ of total RNA, a random hexamer and Omniscript reverse transcriptase (Qiagen). PCR was performed using the following primers: for eNOS, 5'-GCCCTGTACCTCAAGACGCT-3' and $5^{\prime}$-AATACCTGCAGCTTTCCCCA-3', for iNOS, 5'CCCTGCTTTGTGCGAAGTGT-3' and 5'-CCTCATTGGCCAGCTGCTT-3', and for glyceraldehyde-3 phosphate dehydrogenase (GAPDH), 5'-ACCACAGTCCATGCCATCAC-3' and 5'-TCCACCACCCTGTTGCTGTA-3'. PCR of eNOS and iNOS was performed for 35 cycles and that of GAPDH for 30 cycles $\left(94^{\circ} \mathrm{C}\right.$ for $1 \mathrm{~min}, 57^{\circ} \mathrm{C}$ for $1 \mathrm{~min}$ and $72^{\circ} \mathrm{C}$ for $1 \mathrm{~min}$ ) in a $20 \mu \mathrm{l}$ reaction mixture containing cDNA generated from $40 \mathrm{ng}$ of total RNA, $0.2 \mathrm{mmol} / \mathrm{l}$ of each dNTP, $0.4 \mu \mathrm{mol} / \mathrm{l}$ of each primer, and 1 unit of Taq polymerase (Qiagen). 
PCR product was visualized by electrophoresis in $2 \%$ agarose gels and ethidium bromide staining.

\section{2-Deoxyglucose uptake}

2-deoxy-D- $\left[{ }^{3} \mathrm{H}\right]$-glucose (2-DOG) uptake was measured in 3T3-L1 adipocytes cultured on six-well plates according to the method of Sakoda et al. (16). In brief, 3T3-L1 adipocytes were starved for $3 \mathrm{~h}$. Then, glucose-free incubation was performed for $1 \mathrm{~h}$ in Krebs-Ringer-phosphate buffer in the presence of various concentrations of SNP, and 2-DOG uptake was measured.

\section{Subcellular fractionation of 3T3-L1 adipocytes}

3T3-L1 adipocytes were treated with or without $1 \mu \mathrm{mol} / \mathrm{l}$ dexamethasone overnight and then incubated with $100 \mathrm{nmol} / \mathrm{l}$ insulin for $15 \mathrm{~min}$ or with $50 \mathrm{mmol} / \mathrm{l}$ SNP for $1 \mathrm{~h}$ in Krebs-Ringer HEPES buffer. Cells were washed with cold buffer A $(250 \mathrm{mmol} / \mathrm{l}$ sucrose, $20 \mathrm{mmol} / \mathrm{l} \mathrm{HEPES}$, pH 7.4, $1 \mathrm{mmol} / \mathrm{l}$ EDTA, protease inhibitor cocktail) and collected in buffer A, and homogenized using 30 strokes of a Dounce homogenizer. Following the removal of the fat layer, the supernatant from a 30-min $16000 \boldsymbol{g}$ centrifugation was centrifuged at $30000 \boldsymbol{g}$ for $30 \mathrm{~min}$ and then additionally at $40000 \boldsymbol{g}$ for $1 \mathrm{~h}$ to obtain a low density microsomal (LDM) pellet, which was resuspended in HES buffer ( $20 \mathrm{mmol} / \mathrm{l}$ HEPES, pH 7.4, $1 \mathrm{mmol} / \mathrm{l}$ EDTA). The $16000 \boldsymbol{g}$ pellet was washed with HES buffer, resuspended in HES buffer, layered over a $1.12 \mathrm{~mol} / \mathrm{l}$ sucrose cushion, and centrifuged at $100000 \boldsymbol{g}$ for $1 \mathrm{~h}$. The plasma membrane (PM) layer at the interface was collected by centrifugation, and resuspended in HES buffer. Protein concentrations in the samples were determined using BCA protein assay kit. All samples were adjusted to $20 \mu \mathrm{g}$ protein and then immunoblotted with anti-GLUT4 or anti-GLUT1 antibodies. $\mathrm{BCIP} / \mathrm{NBT}$ was used for visualization. Quantitation of the immunoblots was performed with NIH Image software.

\section{Statistical analysis}

Data are presented as means \pm S.E.M. Each treatment was compared with the control and statistical analysis was performed using Student's t-test. A $P<0.01$ was considered as statistically significant.

\section{Results}

\section{Expression of eNOS in 3T3-L1 adipocytes}

Immunoblotting analysis of 3T3-L1 adipocytes confirmed the expression of eNOS in WAT (Fig. 1). The protein levels of eNOS were not altered after treatment
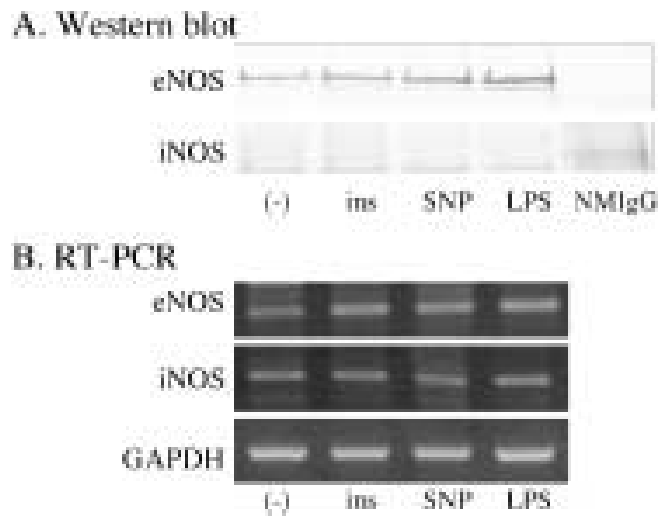

Figure 1 NOS proteins and mRNA in 3T3-L1 adipocytes as detected by Western blotting and PCR. Cells were treated with $100 \mathrm{nmol} / \mathrm{l}$ insulin (ins) for $15 \mathrm{~min}, 50 \mathrm{mmol} / \mathrm{l} \mathrm{SNP}$ for $1 \mathrm{~h}$ or $10 \mu \mathrm{g} / \mathrm{ml}$ LPS for $24 \mathrm{~h}$. (A) eNOS and iNOS proteins were detected by immunoprecipitation and immunoblotting using antieNOS or anti-iNOS antibodies and normal mouse IgG (NMIgG) as a control. (B) mRNAs of eNOS and iNOS were detected by RT-PCR. GAPDH was also examined as an internal control. cont, no treatment.

with insulin or SNP. However, it was not possible to detect iNOS in these conditions. Although LPS was previously reported to increase the expression of iNOS in rat white adipocytes, iNOS was not detected after treatment with $10 \mu \mathrm{g} / \mathrm{ml}$ LPS for $24 \mathrm{~h}$. In vitro, LPS appears to affect iNOS activity in the presence of other cytokines such as tumor necrosis factor- $\alpha$ (TNF- $\alpha$ ) or interferon- $\gamma$ (INF- $\gamma$ ) (17). The results of RT-PCR showed that both eNOS and iNOS are detectable in 3T3-L1 adipocytes, but their mRNA levels did not change after treatment with insulin, SNP or LPS. Thus, eNOS is probably the most essential NOS isoform responsible for NO production at least in our experimental conditions.

\section{Effects of SNP on 2-DOG uptake in 3T3-L1 adipocytes}

We measured the effect of various concentrations of SNP on 2-DOG uptake in 3T3-L1 adipocytes. SNP, between concentrations of $0-60 \mathrm{mmol} / \mathrm{l}$, significantly $(P<0.01)$ increased 2-DOG uptake. The uptake was highest (1.8-fold increase) at $50 \mathrm{mmol} / \mathrm{l} \mathrm{SNP} \mathrm{(Fig.} \mathrm{2A).}$ This dose-dependent curve was parallel to that of NO release from SNP into the culture media (data not shown). SNP showed almost maximal effect on NO release and glucose uptake at the concentration of $50 \mathrm{mmol} / \mathrm{l}$. SNP-stimulated 2-DOG uptake increased significantly after $15 \mathrm{~min}$ of incubation and reached a maximum (1.8-fold) increase after $60 \mathrm{~min}$ (Fig. 2B). To examine whether both insulin and SNP stimulate glucose uptake through the same pathway, 3T3-L1 adipocytes were treated with a combination of $100 \mathrm{nmol} / \mathrm{l}$ insulin and $50 \mathrm{mmol} / \mathrm{l} \mathrm{SNP}$. This combination induced an additive effect on 2-DOG uptake, but not at a 
A

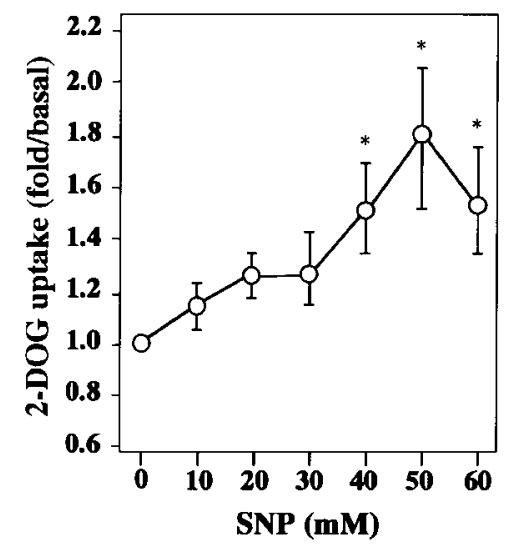

B

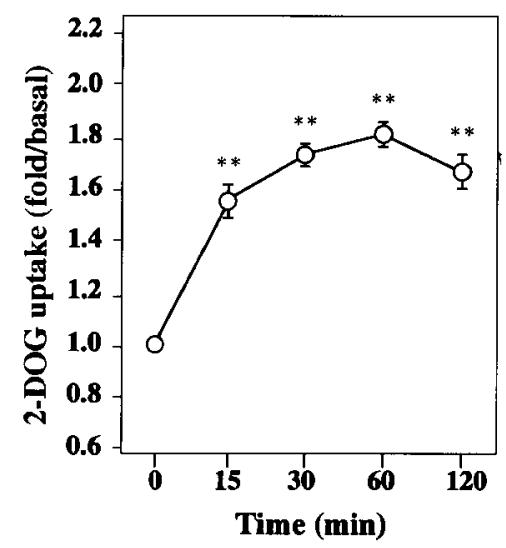

C

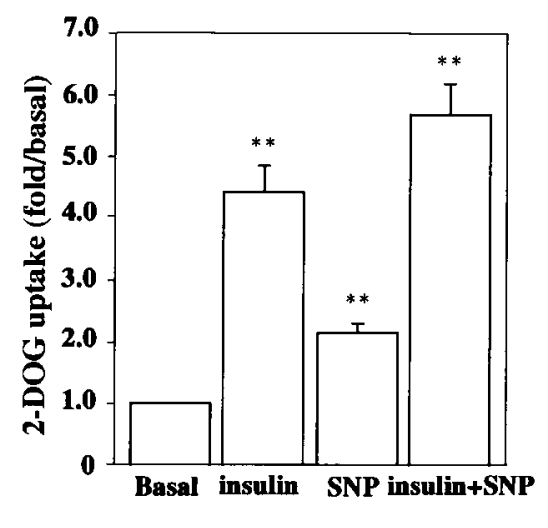

Figure 2 Effects of SNP on 2-DOG uptake in 3T3-L1 adipocytes. (A) The 3T3-L1 adipocytes were incubated with the indicated concentrations of SNP for $1 \mathrm{~h}$. (B) The 3T3-L1 adipocytes were incubated with $50 \mathrm{mmol} / \mathrm{l}$ SNP for the indicated time. (C) The cells were pre-incubated with $50 \mathrm{mmol} / \mathrm{I} \mathrm{SNP}$ for $1 \mathrm{~h}$ and then treated with $100 \mathrm{nmol} / \mathrm{l}$ insulin for $15 \mathrm{~min}$. 2-DOG uptake was assayed in these cells. Data are means \pm S.E.M. of three independent experiments performed in triplicate. ${ }^{\star} P<0.05$, ${ }^{\star \star} P<0.01$ vs basal uptake.

significant level (Fig. 2C), suggesting that both insulin and SNP stimulate glucose uptake through different pathways.

\section{Effect of SNP on phosphorylation of IRS-1 and Akt}

To assess whether SNP affects the insulin signaling pathway, 3T3-L1 adipocytes were incubated with $100 \mathrm{nmol} / \mathrm{l}$ insulin or $50 \mathrm{mmol} / \mathrm{l} \mathrm{SNP}$ for $5,10,15$, $30,60 \mathrm{~min}$, and then phosphorylation of IRS-1 and Akt was determined by Western blotting (Fig. 3). Insulin induced tyrosine phosphorylation of IRS-1 and Ser 473 phosphorylation of Akt after a 5-min incubation. In contrast, $50 \mathrm{mmol} / \mathrm{l} \mathrm{SNP}$ had no effect on phosphorylation of IRS-1 and Akt. These findings suggest that the insulin receptor/Akt pathway is not involved in SNP-dependent glucose uptake.

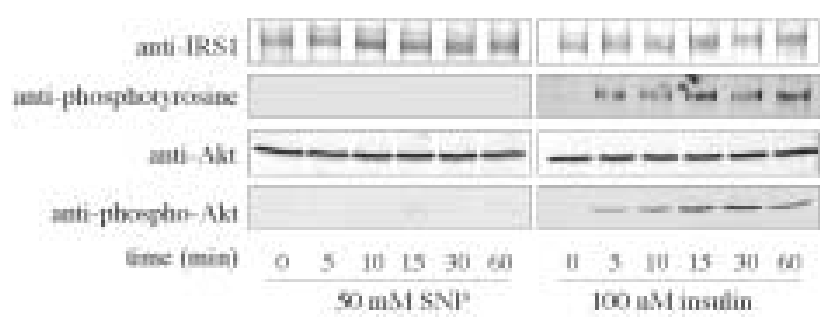

Figure 3 Effect of SNP or insulin on tyrosine phosphorylation of IRS-1 and serine phosphorylation of Akt. The 3T3-L1 adipocytes were incubated with $50 \mathrm{mmol} / \mathrm{l} \mathrm{SNP}$ or $100 \mathrm{nmol} / \mathrm{l}$ insulin for the indicated time. Tyrosine phosphorylation of IRS-1 was detected by immunoprecipitation using anti-IRS-1 antibody and immunoblotting using anti-IRS-1 or anti-phosphotyrosine antibody. Serine 473 phosphorylation of Akt was detected using anti-Akt or antiphosphoAkt (Ser 473) antibody.

\section{Effect of inhibition of NO/guanylate cyclase pathway on SNP-stimulated 2-DOG uptake}

To assess the downstream pathway leading to 2-DOG uptake by SNP, we tested the effect of the NO scavenger CPTIO and the guanylate cyclase inhibitor LY83583. As shown in Fig. 4, pre-treatment of 3T3-L1 adipocytes with $200 \mu \mathrm{mol} / \mathrm{l}$ CPTIO or $1 \mu \mathrm{mol} / \mathrm{l} \mathrm{LY83583}$ for $60 \mathrm{~min}$ significantly reduced $(42 \%$ and $48 \%$ respectively) SNP-stimulated 2-DOG uptake to the basal level, suggesting that SNP-stimulated glucose uptake is mediated by $\mathrm{NO}$ and guanylate cyclase.

\section{Effect of dexamethasone on glucose transport}

To investigate the effect of dexamethasone on SNPstimulated glucose transport, the cells were pretreated overnight with $1 \mu \mathrm{mol} / \mathrm{l}$ dexamethasone. Dexamethasone suppressed both insulin- and SNP-stimulated 2-DOG uptake (45\% and 34\% respectively) (Fig. 5A). Then, we examined the effect of dexamethasone on GLUT4 translocation. Dexamethasone significantly decreased both insulin- and SNP-stimulated GLUT4 translocation (41\% and 31\% respectively) (Fig. 5B). These findings show that dexamethasone may repress GLUT4 translocation and subsequent 2-DOG uptake induced by both insulin and SNP.

\section{Discussion}

Glucose uptake in skeletal muscles may be stimulated via two distinct pathways. One is a pathway stimulated by insulin or growth factors, which leads to PI3K activation. Another pathway is an insulin-independent stimulation by muscle contraction. Both insulin and 


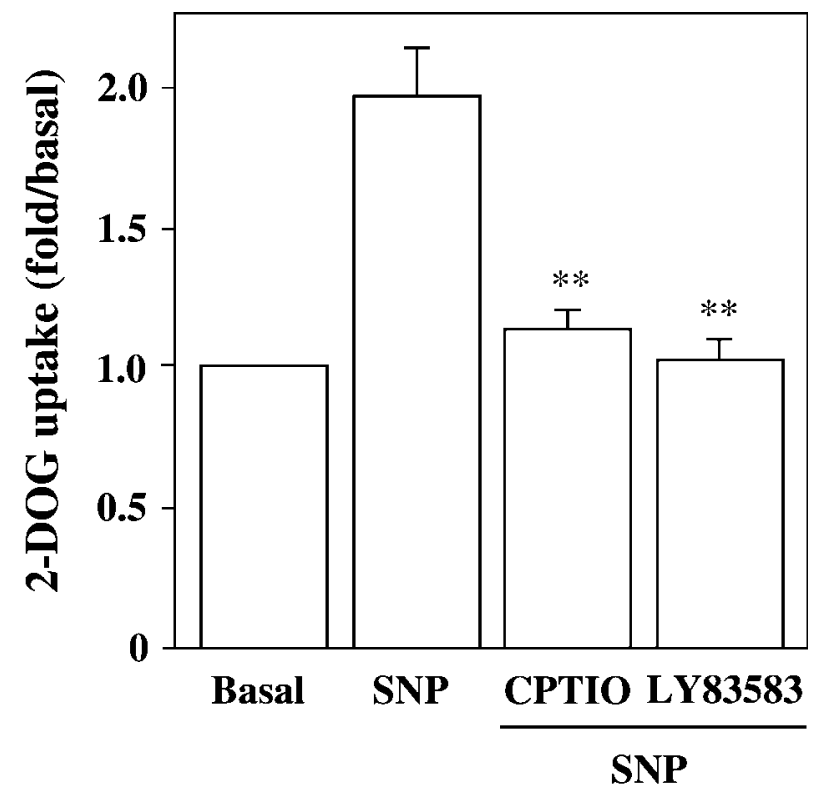

Figure 4 Effect of CPTIO and LY83583 on NO-stimulated 2-DOG uptake. The cells were incubated for $60 \mathrm{~min}$ with CPTIO

$(200 \mu \mathrm{mol} / \mathrm{l})$ or LY83583 $(100 \mathrm{nmol} / \mathrm{l})$ in the presence of $50 \mathrm{mmol} / \mathrm{l}$ SNP. 2-DOG uptake was then assayed. The results are expressed as the fold increase of activation in relation to basal uptake from three independent experiments performed in duplicate. Data are presented as means \pm S.E.M. ${ }^{\star *} P<0.01$ vs glucose uptake by SNP.

muscle contraction have additive effects on glucose transport. A recent study suggested that contractionstimulated glucose uptake is NO dependent in skeletal muscles (7). In the present study, we demonstrated that eNOS is expressed in murine 3T3-L1 adipocytes, and this result is consistent with previous findings in human adipocytes (18). Since generated NO easily dissipates and exerts only local effects, we hypothesized that NO modulates glucose uptake in 3T3-L1 adipocytes in an autocrine fashion. The results of our investigation showed that SNP stimulates glucose uptake in 3T3-L1 adipocytes. The necessary concentration of SNP for stimulation of glucose uptake is similar to that for NO release in culture media. Another NO donor, diethylamine NONOate, also stimulated glucose uptake to a similar extent (data not shown). The fact that the NO scavenger CPTIO inhibited the stimulatory activity of SNP further supports the mediation of NO in the stimulation of glucose uptake by SNP. The effect of NO on glucose uptake in 3T3-L1 adipocytes is similar to its effect in skeletal muscles except for the need of a higher concentration of SNP in adipocytes (8). Moreover, the maximum effect of NO to stimulate glucose uptake is comparable to that of norepinephrine in brown adipocytes (19).

In subsequent experiments, we examined the mechanism of NO stimulation of glucose uptake. Insulin was found to induce GLUT4 translocation and glucose uptake through phosphorylation of IRS-1 or Akt in
3T3-L1 adipocytes. However, NO did not induce phosphorylation of IRS-1 and Akt during the stimulation of glucose uptake. These results suggest that the insulin receptor/Akt pathway is not involved in NO function.

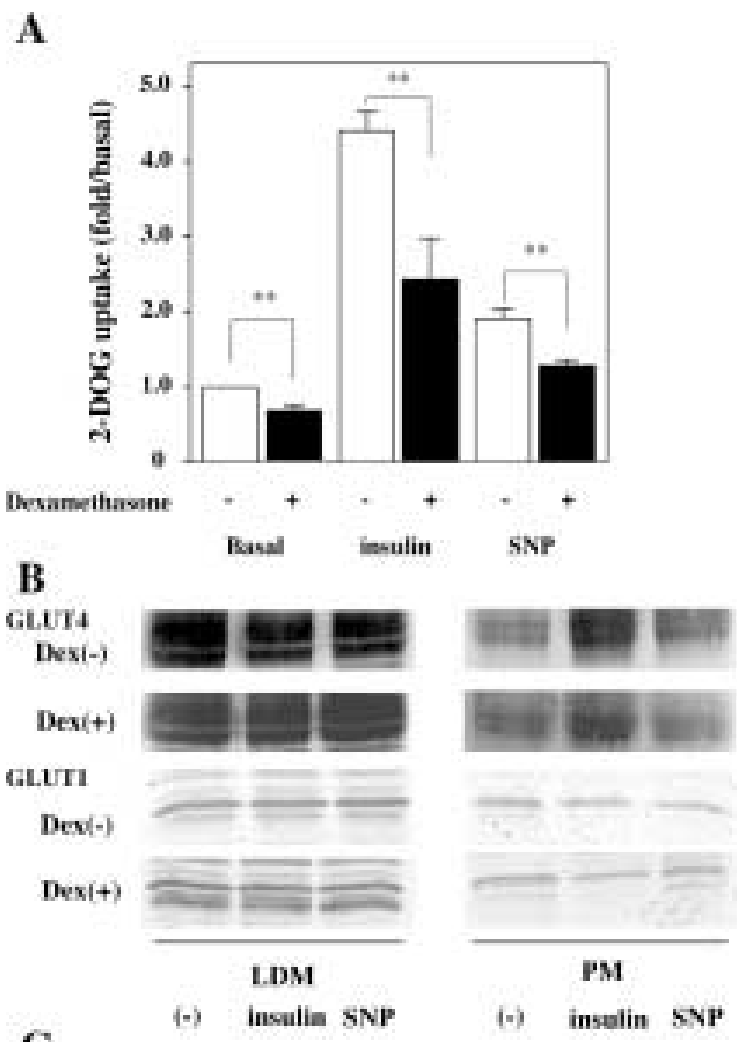

C

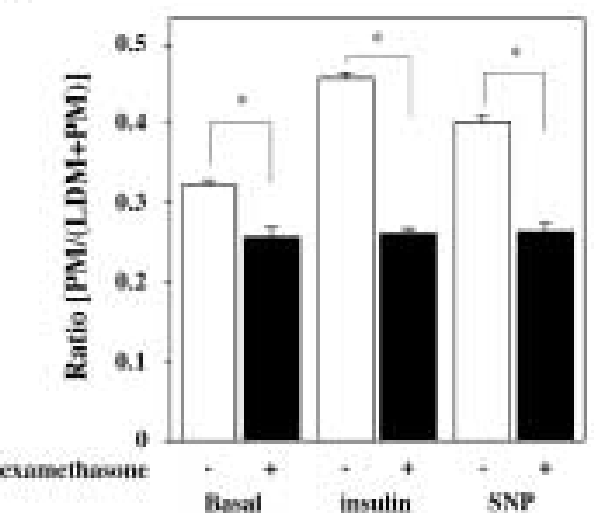

Figure 5 Effect of dexamethasone on insulin- and NO-stimulated glucose transport. The cells were pre-incubated overnight without (open bar) or with (closed bar) dexamethasone $(1 \mu \mathrm{mol} / \mathrm{l})$ and then incubated for $15 \mathrm{~min}$ with $100 \mathrm{nmol} / \mathrm{l}$ insulin or for $60 \mathrm{~min}$ with $50 \mathrm{mmol} / \mathrm{I} \mathrm{SNP.} \mathrm{(A)} \mathrm{2-DOG} \mathrm{uptake} \mathrm{was} \mathrm{then} \mathrm{assayed.} \mathrm{The} \mathrm{results}$ are expressed as the fold increase of activation in relation to basal uptake from three independent experiments performed in triplicate. ${ }^{*} P<0.01$ vs basal uptake. (B) GLUT4 translocation was tested. Protein lysates were fractionated into PM and LDM followed by Western blotting using anti-GLUT4 antibody.

(C) The GLUT4 values represent the ratio between PM GLUT4 and total GLUT4. Data represent the means \pm S.E.M. of three independent experiments. ${ }^{*} P<0.05$ vs basal state. 
In addition, the effect of SNP was additive to that of insulin. Further, a recent study suggested that NO is not involved in the contraction-stimulated glucose uptake in skeletal muscles (8). Considering these observations together, it appears that NO simulates glucose uptake through an insulin-independent and contraction-independent pathway in 3T3-L1 adipocytes. Guanylate cyclase is involved in this pathway as shown by the results of experiments using the guanylate cyclase inhibitor LY83583; this latter finding is consistent with results of a previous study (12).

Dexamethasone is well known to induce insulin resistance in vivo. Three mechanisms have been suggested in dexamethasone-induced insulin resistance. (i) Reduced expression of IRS-1 (20), (ii) reduced phosphorylation of IRS-1 and decreased PI3K activity (21), and (iii) impairment of GLUT4 translocation $(16,22)$. In this study, dexamethasone was also found to reduce NO-stimulated glucose uptake in 3T3-L1 adipocytes. The fact that IRS-1 and PI3K are not involved in NO-stimulated glucose uptake suggests that dexamethasone reduces glucose uptake in 3T3-L1 adipocytes by affecting GLUT4 translocation. Taken together, these findings suggest that NO-stimulated glucose uptake in adipocytes occurs through an insulin-independent pathway and that GLUT4 translocation is involved in this NO-stimulated mechanism.

Although eNOS has been regarded as a strictly $\mathrm{Ca}^{2+} /$ calmodulin-dependent enzyme (23), recent studies have shown the existence of other regulation pathways. eNOS is phosphorylated and activated by Akt in endothelial cells $(24,25)$ and insulin activates Akt and stimulates the production of NO in rat adipocytes (26). Vascular endothelial growth factor (VEGF) and estrogen also stimulated eNOS through Akt activation $(27,28)$. However, bradykinin stimulates eNOS through mitogen-activated protein kinase $(29,30)$. With regards to non-hormonal stimuli, exercise (7) and shear stress can activate eNOS through Akt or AMP-activated kinase $(7,31,32)$. eNOS can be activated by several stimuli in a calcium-independent fashion. In WAT, several types of stimuli can activate eNOS expression leading to increased glucose uptake.

In summary, in the present study, we demonstrated for the first time that NO mediates glucose transport in 3T3-L1 adipocytes. Our results also indicate that the effect of NO is independent of the insulin signaling pathway.

\section{Acknowledgements}

This work was supported in part by a Grant-in-Aid from Mie Medical Research Foundation (to K N and T N) and a Grant-in-Aids for Scientific Research from the Ministry of Education, Science, Sports and Culture in Japan (to $\mathrm{H} \mathrm{W}$ and $\mathrm{T} \mathrm{N}$ ).

\section{References}

1 Balon TW \& Nadler JL. Nitric oxide release is present from incubated skeletal muscle preparations. Journal of Applied Physiology 199477 2519-2521.

2 Baron AD, Zhu JS, Marshall S, Irsula O, Brechtel G \& Keech C. Insulin resistance after hypertension induced by the nitric oxide synthesis inhibitor L-NMMA in rats. American Journal of Physiology 1995269 E709-E715.

3 Balon TW \& Nadler JL. Evidence that nitric oxide increases glucose transport in skeletal muscle. Journal of Applied Physiology 199782 359-363.

4 Young ME, Radda GK \& Leighton B. Nitric oxide stimulates glucose transport and metabolism in rat skeletal muscle in vitro. Biochemical Journal 1997322 223-228.

5 Etgen GJ Jr, Fryburg DA \& Gibbs EM. Nitric oxide stimulates skeletal muscle glucose transport through a calcium/contractionand phosphatidylinositol-3-kinase-independent pathway. Diabetes 199746 1915-1919.

6 Duplain H, Burcelin R, Sartori C, Cook S, Egli M, Lepori M et al. Insulin resistance, hyperlipidemia, and hypertension in mice lacking endothelial nitric oxide synthase. Circulation $2001 \mathbf{1 0 4}$ 342-345.

7 Roberts CK, Barnard RJ, Scheck SH \& Balon TW. Exercisestimulated glucose transport in skeletal muscle is nitric oxide dependent. American Journal of Physiology 1997273 E220-E225.

8 Higaki Y, Hirshman MF, Fujii \& Goodyear LJ. Nitric oxide increases glucose uptake through a mechanism that is distinct from the insulin and contraction pathways in rat skeletal muscle. Diabetes $200150241-247$.

9 Palmer RM, Ashton DS \& Moncada S. Vascular endothelial cells synthesize nitric oxide from L-arginine. Nature 1988333 $664-666$.

10 Wang Y \& Marsden PA. Nitric oxide synthases: gene structure and regulation. Advances in Pharmacology 199534 71-90.

11 Kobzik L, Reid MB, Bredt DS \& Stamler JS. Nitric oxide in skeletal muscle. Nature 1994372 546-548.

12 McDonald LJ \& Murad F. Nitric oxide and cyclic GMP signaling. Proceedings of the Society for Experimental Biology and Medicine $19962111-6$.

13 Nagashima T, Ohinata H \& Kuroshima A. Involvement of nitric oxide in noradrenaline-induced increase in blood flow through brown adipose tissue. Life Science 199454 17-25.

14 Nisoli E, Tonello C, Briscini L \& Carruba MO. Inducible nitric oxide synthase in rat brown adipocytes: implications for blood flow to brown adipose tissue. Endocrinology 1997138 676-682.

15 Giordano A, Tonello C, Bulbarelli A, Cozzi V, Cinti S, Carruba MO et al. Evidence for a functional nitric oxide synthase system in brown adipocyte nucleus. FEBS Letters $2002 \mathbf{5 1 4} 135-140$.

16 Sakoda H, Ogihara T, Anai M, Funaki M, Inukai K, Katagiri H et al. Dexamethasone-induced insulin resistance in 3T3-L1 adipocytes is due to inhibition of glucose transport rather than insulin signal transduction. Diabetes 200049 1700-1708.

17 Kapur S, Marcotte B \& Marette A. Mechanism of adipose tissue iNOS induction in endotoxemia. American Journal of Physiology 1999276 E635-E641.

18 Ribiere C, Jaubert AM, Gaudiot N, Sabourault D, Marcus ML, Boucher JL et al. White adipose tissue nitric oxide synthase: a potential source for NO production. Biochemical and Biophysical Research Communications 1996222 706-712.

19 Shimizu Y, Kielar D, Minokoshi Y \& Shimazu T. Noradrenaline increases glucose transport into brown adipocytes in culture by a mechanism different from that of insulin. Biochemical Journal 1996314 485-490.

20 Turnbow MA, Keller SR, Rice KM \& Garner CW. Dexamethasone down-regulation of insulin receptor substrate-1 in 3T3-L1 adipocytes. Journal of Biological Chemistry 1994269 2516-2520.

21 Saad MJ, Folli F, Kahn JA \& Kahn CR. Modulation of insulin receptor, insulin receptor substrate-1, and phosphatidylinositol 
3-kinase in liver and muscle of dexamethasone-treated rats. Journal of Clinical Investigation 199392 2065-2072.

22 Weinstein SP, Paquin T, Pritsker A \& Haber RS. Glucocorticoidinduced insulin resistance: dexamethasone inhibits the activation of glucose transport in rat skeletal muscle by both insulin- and non-insulin-related stimuli. Diabetes $1995 \mathbf{4 4} 441-445$.

23 Busse R \& Mülsch A. Calcium-dependent nitric oxide synthesis in endothelial cytosol is mediated by calmodulin. FEBS Letters 1990 $265133-136$.

24 Fulton D, Gratton JP, McCabe TJ, Fontana J, Fujio Y, Walsh K et al. Regulation of endothelium-derived nitric oxide production by the protein kinase Akt. Nature 1999399 597-601.

25 Dimmeler S, Fleming I, Fisslthaler B, Hermann C, Busse R \& Zeiher AM. Activation of nitric oxide synthase in endothelial cells by Akt-dependent phosphorylation. Nature 1999399 601-605.

26 Ribiere C, Jaubert AM, Sabourault D, Lacasa D \& Giudicelli Y. Insulin stimulates nitric oxide production in rat adipocytes. Biochemical and Biophysical Research Communications 2002291 394-399.

27 Michell BJ, Griffiths JE, Mitchelhill KI, Rodriguez-Crespo I, Tiganis T, Bozinovski S et al. The Akt kinase signals directly to endothelial nitric oxide synthase. Current Biology 19999 845-848.
28 Chen Z, Yuhanna IS, Galcheva-Gargova Z, Karas RH, Mendelsohn ME \& Shaul PW. Estrogen receptor alpha mediates nongenomic activation of eNOS by estrogen. Journal of Clinical Investigation $1999 \mathbf{1 0 3} 401-406$.

29 Bernier SG, Haldar S \& Michel T. Bradykinin-regulated interactions of the mitogen-activated protein kinase pathway with the endothelial nitric-oxide synthase. Journal of Biological Chemistry $200027530707-30715$.

30 Harris MB, Ju H, Venema VJ, Liang H, Zou R, Michell BJ et al. Reciprocal phosphorylation and regulation of endothelial nitricoxide synthase in response to bradykinin stimulation. Journal of Biological Chemistry 2001276 16587-16591.

31 Chen ZP, Mitchelhill KI, Michell BJ, Stapleton D, Rodriguez-Crespo I, Witters LA et al. AMP-activated protein kinase phosphorylation of endothelial NO synthase. FEBS Letters $1999 \mathbf{4 4 3} 285-289$.

32 Boo YC, Sorescu G, Boyd N, Shiojima I, Walsh K, Du J et al. Shear stress stimulates phosphorylation of endothelial nitric-oxide synthase at Ser1179 by Akt-independent mechanisms: role of protein kinase A. Journal of Biological Chemistry 2002277 3388-3396.

Received 20 November 2002

Accepted 3 March 2003 